\title{
Vaginal tolerance of CT based image-guided high-dose rate interstitial brachytherapy for gynecological malignancies
}

\author{
Naoya Murakami ${ }^{\text {* }}$, Takahiro Kasamatsu ${ }^{2}$, Minako Sumi ${ }^{1}$, Ryoichi Yoshimura ${ }^{3}$, Ken Harada ${ }^{1}$, Mayuka Kitaguchi ${ }^{1}$, \\ Shuhei Sekii ${ }^{1}$, Kana Takahashi ${ }^{1}$, Kotaro Yoshio ${ }^{1}$, Koji Inaba ${ }^{1}$, Madoka Morota ${ }^{1}$, Yoshinori Ito ${ }^{1}$ and Jun Itami ${ }^{1}$
}

\begin{abstract}
Background: Purpose of this study was to identify predictors of vaginal ulcer after $C T$ based three-dimensional image-guided high-dose-rate interstitial brachytherapy (HDR-ISBT) for gynecologic malignancies.

Methods: Records were reviewed for 44 female (14 with primary disease and 30 with recurrence) with gynecological malignancies treated with HDR-ISBT with or without external beam radiation therapy. The HDR-ISBT applicator insertion was performed with image guidance by trans-rectal ultrasound and CT.

Results: The median clinical target volume was $35.5 \mathrm{ml}(2.4-142.1 \mathrm{ml})$ and the median delivered dose in equivalent dose in 2 Gy fractions ( $\left(E_{2} D_{2}\right.$ ) for target volume $D_{90}$ was $67.7 \mathrm{~Gy}$ (48.8-94.2 Gy, doses of external-beam radiation therapy and brachytherapy were combined). For re-irradiation patients, median $E Q D_{2}$ of $D_{2 c c}$ for rectum and bladder, $D_{0.5 c c}, D_{1 c c}, D_{2 c c}, D_{4 c c}, D_{6 c c}$ and $D_{8 c c}$ for vaginal wall was $91.1 \mathrm{~Gy}, 100.9 \mathrm{~Gy}, 260.3 \mathrm{~Gy}, 212.3 \mathrm{~Gy}, 170.1 \mathrm{~Gy}$, 117.1 Gy, 105.2 Gy, and 94.7 Gy, respectively. For those without prior radiation therapy, median $\mathrm{EQD}_{2}$ of $\mathrm{D}_{2 \mathrm{cc}}$ for rectum and bladder, $D_{0.5 c c} D_{1 c c,} D_{2 c c,} D_{4 c c} D_{6 c c}$ and $D_{8 c c}$ for vaginal wall was $56.3 \mathrm{~Gy}, 54.3 \mathrm{~Gy}, 147.4 \mathrm{~Gy}, 126.2 \mathrm{~Gy}, 108.0 \mathrm{~Gy}$, 103.5 Gy, 94.7 Gy, and $80.7 \mathrm{~Gy}$, respectively. Among five patients with vaginal ulcer, three had prior pelvic radiation therapy in their initial treatment and three consequently suffered from fistula formation. On univariate analysis, re-irradiation and vaginal wall $\mathrm{D}_{2 \mathrm{cc}}$ in $\mathrm{EQD}_{2}$ was the clinical predictors of vaginal ulcer $(p=0.035$ and $p=0.025$, respectively). The ROC analysis revealed that vaginal wall $D_{2 c c}$ is the best predictor of vaginal ulcer. The 2-year incidence rates of vaginal ulcer in the patients with vaginal wall $D_{2 c c}$ in $E Q D_{2}$ equal to or less than 145 Gy and over 145 Gy were $3.7 \%$ and 23.5\%, respectively, with a statistically significant difference $(p=0.026)$.
\end{abstract}

Conclusions: Re-irradiation and vaginal $D_{2 c c}$ is a significant predictor of vaginal ulcer after HDR-ISBT for gynecologic malignancies. Three-dimensional image-guided treatment planning should be performed to ensure adequate target coverage while minimizing vaginal $D_{2 c c}$ in order to avoid vagina ulcer.

Keywords: Gynecologic brachytherapy, High-dose-rate brachytherapy, Interstitial brachytherapy, Vaginal ulcer

\section{Introduction}

High-dose rate intracavitary brachytherapy (HDR-ICBT) is an established method in the management of gynecological malignancies, especially in cervical cancer. However, in patients with a narrow vagina, short uterine cavity, distal vaginal extension, and bulky tumors in which the optimal dose distribution cannot be obtained by intracavitary

\footnotetext{
* Correspondence: namuraka@ncc.go.jp

'Department of Radiation Oncology, National Cancer Center Hospital, 5-1-1, Tsukiji Chuo-ku, Tokyo 104-0045, Japan

Full list of author information is available at the end of the article
}

brachytherapy (ICBT), interstitial brachytherapy (ISBT) is employed. Also in patients with bulky postoperative central pelvic recurrence, ISBT has proven to be effective [1-5]. With the advent of image-guided brachytherapy it has become possible to assess the dose volume histogram (DVH) in brachytherapy. Several studies have validated the $\mathrm{D}_{2 \mathrm{cc}}$ as a predictor of rectal and bladder toxicities for ICBT [6] or for ISBT [7]. $\mathrm{D}_{2 \mathrm{cc}}$ of the rectum and bladder have been introduced into daily clinical practice of gynecological image-guided brachytherapy. However in ICRU 38 vagina was not recognized as organ at risk 
during brachytherapy tough it is adjacent to target volume and radioactive sources [8].

The purpose of this study was to retrospectively analyze the incidence of vaginal morbidities after HDRISBT for gynecological cancers and to find clinical and dosimetric factors which affect the incidence of the vaginal morbidities.

\section{Methods}

The inclusion criteria of this single institutional retrospective study were patients with gynecological malignancies who were treated by HDR-ISBT with or without external beam radiation therapy (EBRT) with a followup length exceeding 6 months or more. Patients with distant metastasis outside of pelvis were excluded from current study. HDR-ISBT was applied for both primary and salvage intents. Patients with superficial vaginal disease with thickness less than $5 \mathrm{~mm}$ were treated with HDR-ICBT and did not treated by HDR-ISBT; therefore these patients were not included in this analysis. Also HDR-ISBT was not applied for those patients who had distant metastasis or for those patients with far advanced tumors which had not responded to EBRT performed before HDR-ISBT. These patients were treated with EBRT alone. One patient who succumbed to progressive cancer in 5.5 months after ISBT was also excluded in this analysis. The medical records of all patients with gynecological malignancies treated with HDR-ISBT at the National Cancer Center Hospital, Tokyo, Japan, between 2008 and 2011 were retrieved and 44 patients were included in this study.

In the patients without prior pelvic irradiation, pelvic EBRT was delivered before HDR-ISBT. The common EBRT portals were whole pelvic irradiation including gross tumor volume (GTV) with adequate margin as well as the pelvic lymph nodes basin up to the level of the common iliac (L4/5 junction). If the tumor involved the lower third of the vagina, or there were clinically palpable inguinal nodes, inguinal regions were also included in the EBRT portals. The initial 20-40 Gy was delivered to the whole pelvis with a 4-fields box technique and then pelvic irradiation was administered with a central shield being employed to reduce exposure of organs at risk (OAR). The total dose delivered to the pelvic side wall was up to $50 \mathrm{~Gy}$ in a conventional fractionation. In patients with a history of prior pelvic radiation therapy or in feeble elderly patients, no EBRT or smaller EBRT fields with a reduced total dose were employed. HDRISBT was basically performed after the central shield was inserted. However for those patients treated without EBRT, HDR-ISBT was applied as solitary radiotherapy modality. The detailed procedure of gynecological HDRISBT was described elsewhere [9]. In brief, transperineal needle applicator insertion was performed under either general or local anesthesia with the patients in lithotomy position and guided by trans-rectal ultrasound (TRUS) or CT which can be taken with the patients lying in lithotomy position with the applicators in place. For advanced large disease, a Syed-Neblett perineal template (Best Medical International, Inc., Springfield, VA) was used in order to sufficiently cover lateral disease extent. For rather localized small disease, with limited parametrial and/or paracolpial invasion, free-hand needle applicator insertion with or without a vaginal applicator was used with fewer needles inserted compared to the SyedNeblett perineal template. Treatment planning was performed with brachytherapy planning system (Oncentra ${ }^{\circ}$ Nucletron, Veenendaal, The Netherlands) using CT images taken by the large bore CT simulator (Aquilion LG $^{\oplus}$, Toshiba, Tokyo, Japan), which allows imaging of the patients in lithotomy position. Although different applicator was used throughout the patients, the calculation method applied was the same. The clinical target volume (CTV) was defined based on the CT image obtained after needle insertion, as well as physical examination immediately before needle insertion, the intra-operative TRUS image and the most recent MRI were also taken into account. Reference points were set on the surface of CTV and prescribed dose was delivered to those points. HDR-ISRT treatment plan was calculated initially by geometrical optimization or volume optimization and then manual graphical modification was followed to enclose the CTV by the prescription dose while minimizing high dose to OAR. The median HDR-ISBT dose was 24 Gy (range, 18-54 Gy), and median HDR-ISBT dose per fraction was 6 Gy (range, 4-6 Gy). HDR-ISBT was performed twice daily with each fraction 6 hours apart. HDR-ISBT was performed with MicroSelectron HDR (Nucletron, Veenendaal, The Netherlands) using Ir-192.

At the discretion of the attending physician, weekly CDDP $40 \mathrm{mg} / \mathrm{m}^{2}$ was used in 10 patients concurrently with EBRT. In general, patients with bulky disease, good performance status and adequate organ function were selected for the candidate for the administration of concurrent chemoradiation. Patients were seen in follow up 1 week after HDR-ISBT for a skin check, then every 1-2 months for 2 years, every 3-4 months for 5 years, and every 6-12 months thereafter.

When adding doses of EBRT, HDR-ISBT, and HDRICBT, we used the equivalent dose in 2 Gy fractions $\left(E Q D_{2}\right)$ according to the LQ model $[10,11]$. For reirradiated patients, prior central pelvic EBRT doses were also added to $\mathrm{EQD}_{2}$ for OARs. For those who had prior HDR-ICBT without DVH parameters of OARs because of lack of three dimensional dose calculations, it was difficult to estimate $\mathrm{EQD}_{2}$ for OARs. Therefore, prescribed dose for tumor in $\mathrm{EQD}_{2}(\alpha / \beta=10)$ was converted to $\mathrm{EQD}_{2}$ for late responding tissue $(\alpha / \beta=3)$ and added 
together. Time interval between prior RT and the current RT was not taken into consideration in this analysis.

Rectum and bladder were contoured as a whole organ. Vaginal wall was extracted with a thickness of $4 \mathrm{~mm}$ on all CT images according to the Vienna group [12]. As for rectum and bladder, dosimetric parameter of $D_{2 \mathrm{cc}}$ was used because these values have been validated by several studies [6-8]. On the other hand, there is no validated parameter for vaginal dose; therefore $D_{0.5 \mathrm{cc}}, D_{1 \mathrm{cc}}$, $D_{4 \mathrm{cc}}, D_{6 \mathrm{cc}}$, and $\mathrm{D}_{8 \mathrm{cc}}$ were calculated along with $\mathrm{D}_{2 \mathrm{cc}}$ for vaginal wall dose volume parameters.

Late vaginal morbidities were retrospectively evaluated according to LENT-SOMA scales [13]. Because morbidity scores were evaluated retrospectively in this study, we focused on only vaginal ulcer which could be regarded as one of the severest symptoms and could be retrieved accurately from medical records.

Student's unpaired t-test was used to compare the continuous variables and Pearson's chi-square test to compare categorical variables. A $p$ value of $<0.05$ was considered as statistically significant. In addition, calculation of the area under the curve (AUC) of receiver operating characteristics (ROC) was used to determine the most predictive dosimetric parameter of vaginal ulcer. The predictive values of parameters were evaluated based on the AUC. The optimal threshold for each parameter was defined as the point yielding the minimal value for $(1-\text { sensitivity })^{2}+(1-\text { specificity })^{2}$, which is the point on the ROC curve closest to the upper left-hand corner [14]. The obtained cutoff point was used for dividing patients into two groups and the incidences of vaginal ulcer were calculated by KaplanMeier method with the difference evaluated by log-lank test. All statistical analyses were performed using SPSS Statistics version 18.0 (SAS Institute, Tokyo, Japan).

This retrospective study was approved by the institutional review board of the National Cancer Center.

\section{Results}

There were 44 patients who met the eligibility criteria and 36 patients were alive at the time of the analysis (May 2012). The median follow-up length of living patients was 18.3 months (range, 7.6-39.5 months). The pretreatment characteristics of the 44 patients included in this study are summarized in Table 1 . Median age was 56 years (range, 25-89 years). HDR-ISBT was applied as the primary therapy in 14 patients $(31.8 \%)$ and as the salvage therapy in 30 patients (68.2\%). Eight patients (18.2\%) had previously received pelvic irradiation, in the form of EBRT and/or ICBT. Twenty four patients were treated with Syed-Neblett perineal template, 17 with free-hand with vaginal applicator and three with freehand without vaginal applicator. Treatment details are
Table 1 Patients characteristics $(n=44)$

\begin{tabular}{|c|c|c|}
\hline & & Patients (n) \\
\hline Median age (years, range) & & $56(25-89)$ \\
\hline \multirow[t]{5}{*}{ Primary site } & Cervix & $24(54.6 \%)$ \\
\hline & Vagina & $12(27.3 \%)$ \\
\hline & Corpus & $5(11.3 \%)$ \\
\hline & Ovary & $2(4.5 \%)$ \\
\hline & Vulva & $1(2.3 \%)$ \\
\hline \multirow[t]{3}{*}{ Primary therapy } & & $14(31.8 \%)$ \\
\hline & Cervical cancer & $4(9.1 \%)$ \\
\hline & Vaginal cancer & $10(22.7 \%)$ \\
\hline \multirow[t]{4}{*}{ Salvage therapy } & & $30(68.2 \%)$ \\
\hline & Post ope regidual tumor & $5(11.4 \%)$ \\
\hline & Post ope recurrent tumor & $21(47.7 \%)$ \\
\hline & Post RT recurrent tumor & $4(9.1 \%)$ \\
\hline \multirow[t]{3}{*}{ Histology } & $\mathrm{Scc}$ & $25(56.8 \%)$ \\
\hline & Adeno & $16(36.4 \%)$ \\
\hline & Others & $3(6.8 \%)$ \\
\hline \multirow[t]{2}{*}{ Prior pelvic $\mathrm{RT}^{*}$} & Yes & $8(18.2 \%)$ \\
\hline & No & $36(81.8 \%)$ \\
\hline Median tumor size (cm, range) & & $3.6(1.0-8.0)$ \\
\hline \multirow[t]{2}{*}{ Pelvic $\mathrm{LN}^{\dagger}$ metastais } & Yes & $11(25 \%)$ \\
\hline & No & $33(75 \%)$ \\
\hline
\end{tabular}

${ }^{*} R T$ radiation therapy.

${ }^{\dagger} L N$ lymph node.

summarized in Table 2. Ten patients underwent concurrent chemotherapy. In most cases HDR-ISBT dose per fraction was $6 \mathrm{~Gy}$. Median total EQD 2 of $\mathrm{CTV} \mathrm{D}_{90}$ was 67.7 Gy. Median $\mathrm{EQD}_{2}$ of $\mathrm{D}_{2 \mathrm{cc}}$ for rectum and bladder was $60.8 \mathrm{~Gy}$ and $58.1 \mathrm{~Gy}$, respectively. Median EQD 2 of $\mathrm{D}_{0.5 \mathrm{cc}}, \mathrm{D}_{1 \mathrm{cc}}, \mathrm{D}_{2 \mathrm{cc}}, \mathrm{D}_{4 \mathrm{cc}}, \mathrm{D}_{6 \mathrm{cc}}$, and $\mathrm{D}_{8 \mathrm{cc}}$ for vaginal wall were 210.7 Gy, 167.3 Gy, 131.5 Gy, 111.6 Gy, 100.0 Gy, and $83.2 \mathrm{~Gy}$, respectively. Table 3 shows EQD 2 of rectum, bladder and vaginal wall for the patients with or without prior pelvic radiation therapy. For re-irradiation patients, median $\mathrm{EQD}_{2}$ of $\mathrm{D}_{2 \mathrm{cc}}$ for rectum and bladder, $\mathrm{D}_{0.5 \mathrm{cc}}, \mathrm{D}_{1 \mathrm{cc}}, \mathrm{D}_{2 \mathrm{cc}}, \mathrm{D}_{4 \mathrm{cc}}, \mathrm{D}_{6 \mathrm{cc}}$ and $\mathrm{D}_{8 \mathrm{cc}}$ for vaginal wall was $91.1 \mathrm{~Gy}, 100.9 \mathrm{~Gy}, 260.3 \mathrm{~Gy}, 212.3 \mathrm{~Gy}, 170.1 \mathrm{~Gy}$, 117.1 Gy, 105.2 Gy, and 94.7 Gy, respectively. For those without prior radiation therapy, median $\mathrm{EQD}_{2}$ of $\mathrm{D}_{2 \mathrm{cc}}$ for rectum and bladder, $D_{0.5 \mathrm{cc}}, \mathrm{D}_{1 \mathrm{cc}}, \mathrm{D}_{2 \mathrm{cc}}, \mathrm{D}_{4 \mathrm{cc}}, \mathrm{D}_{6 \mathrm{cc}}$ and $\mathrm{D}_{8 \mathrm{cc}}$ for vaginal wall was $56.3 \mathrm{~Gy}, 54.3 \mathrm{~Gy}, 147.4 \mathrm{~Gy}$, 126.2 Gy, 108.0 Gy, 103.5 Gy, 94.7 Gy, and 80.7 Gy, respectively (Table 3 ). In $\mathrm{EQD}_{2}$ of $\mathrm{D}_{2 \mathrm{cc}}$ for rectum, bladder and vaginal wall the difference was statistically significant $(p<0.001, p<0.001$, and $p=0.001$, respectively).

As for late morbidities of vagina, five patients experienced vaginal ulcer after HDR-ISBT. All of vaginal ulcer occurred within two years after completion of the HDRISBT. Patient characteristics and objective/management 
Table 2 Treatment details $(n=44)$

\begin{tabular}{|c|c|}
\hline & Median range \\
\hline Central pelvic dose of EBRT ${ }^{*}(\mathrm{~Gy})$ & $30(0-50)$ \\
\hline No. of needles used in $\mathrm{HDR}^{-I S B T^{\dagger}}$ & $15(5-29)$ \\
\hline${\mathrm{HDR}-I S B T^{\dagger}}_{\text {fractions }}$ & $4(3-9)$ \\
\hline HDR-ISBT $^{\dagger}$ dose per fraction (Gy) & $6(4-6)$ \\
\hline $\mathrm{CTV}^{\dagger+}(\mathrm{ml})$ & $35.1(2.4-142.1)$ \\
\hline $\mathrm{CTV}^{+\dagger} \mathrm{D}_{90}$ in $\mathrm{EQD}_{2}^{\|}(\mathrm{Gy})$ & $67.7(48.8-94.2)$ \\
\hline Rectum $\mathrm{D}_{2 \Subset c}{ }^{\natural}$ in $\mathrm{EQD}_{2}{ }^{\|}$(Gy) & $60.8(30.5-114.3)$ \\
\hline Bladder $\mathrm{D}_{2 \mathrm{cc}}{ }^{\mathfrak{q}}$ in $\mathrm{EQD}_{2} \|$ (Gy) & $58.1(7.3-120.3)$ \\
\hline Vaginal wall $\mathrm{D}_{0.5 \mathrm{cc}}{ }^{\mathbb{q}}$ in $\mathrm{EQD}_{2}{ }^{\|}(\mathrm{Gy})$ & $210.7(51.5-468.1)$ \\
\hline Vaginal wall $\mathrm{D}_{1 \subset c}{ }^{\natural}$ in $\mathrm{EQD}_{2}^{\|}(\mathrm{Gy})$ & $167.3(49.9-352.1)$ \\
\hline Vaginal wall $\mathrm{D}_{2{ }^{c}}{ }^{\natural}$ in $\mathrm{EQD}_{2}{ }^{\|}$(Gy) & $131.5(43.7-294.4)$ \\
\hline Vaginal wall $\mathrm{D}_{4 c c}{ }^{\natural}$ in $\mathrm{EQD}_{2}^{\|}(\mathrm{Gy})$ & $111.6(34.0-200.8)$ \\
\hline Vaginal wall $\mathrm{D}_{6 c c}{ }^{\natural}$ in $\mathrm{EQD}_{2} \|$ (Gy) & $100.0(20.4-173.7)$ \\
\hline Vaginal wall $\mathrm{D}_{8 c c^{\natural}}$ in $\mathrm{EQD}_{2}{ }^{\|}$(Gy) & $83.2(10.3-144.4)$ \\
\hline \multicolumn{2}{|l|}{ Concurrent chemotherapy } \\
\hline Yes & 10 patients \\
\hline No & 34 patients \\
\hline \multicolumn{2}{|c|}{ 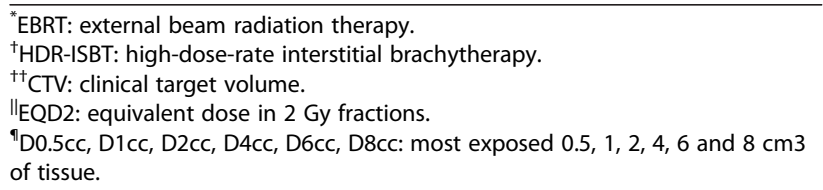 } \\
\hline
\end{tabular}

Table 3 DVH parameters for bladder and vaginal wall with or withour prior radiation therapy

\begin{tabular}{|c|c|c|c|}
\hline & $\begin{array}{l}\text { Prior pelvic } \\
\mathrm{RT}^{\prime}(+)(\mathrm{n}=8)\end{array}$ & $\begin{array}{l}\text { Prior pelvic } \\
\operatorname{RT}^{\top}(-)(n=36)\end{array}$ & $p$ value \\
\hline $\begin{array}{l}\text { eMedian rectum } \mathrm{D}_{2 c c}{ }^{\dagger} \\
\left(\mathrm{EQD}_{2}^{*}, \mathrm{~Gy} \text {, range) }\right.\end{array}$ & 91.1 (71.0-114.3) & $56.3(30.5-82.7)$ & $<0.001^{*}$ \\
\hline $\begin{array}{l}\text { Median bladder } \mathrm{D}_{2 c c}{ }^{+} \\
\left(\mathrm{EQD2}{ }^{*}, \mathrm{~Gy}, \text { range }\right)\end{array}$ & $100.9(69.7-120.3)$ & $54.3(7.3-82.7)$ & $<0.001^{*}$ \\
\hline $\begin{array}{l}\text { Median vaginal wall } \mathrm{D}_{0.5 c c}{ }^{\dagger} \\
\left(\mathrm{EQD2}{ }^{*}, \mathrm{~Gy} \text {, range) }\right.\end{array}$ & $260.3(59.9-349.3)$ & $147.4(47.9-267.3)$ & 0.109 \\
\hline $\begin{array}{l}\text { Median vaginal wall } \mathrm{D}_{1 \subset c}{ }^{+} \\
\text {(EQD2*, Gy, range) }\end{array}$ & $212.3(58.2-277.5)$ & $126.2(33.6-182.7)$ & 0.013 \\
\hline $\begin{array}{l}\text { Median vaginal wall } \mathrm{D}_{2 \mathrm{cc}}{ }^{\dagger} \\
\text { (EQD2*, Gy, range) }\end{array}$ & $170.1(56.6-247.5)$ & $108.0(31.7-150.9)$ & $0.001^{*}$ \\
\hline $\begin{array}{l}\text { Median vaginal wall } \mathrm{D}_{4 c c}{ }^{\dagger} \\
\text { (EQD2*, Gy, range) }\end{array}$ & $117.1(34.0-200.8)$ & $103.5(39.1-139.4)$ & 0.139 \\
\hline $\begin{array}{l}\text { Median vaginal wall } \mathrm{D}_{6 c c}{ }^{+} \\
\left(\mathrm{EQD2} 2^{*}, \mathrm{~Gy} \text {, range) }\right.\end{array}$ & $105.2(33.0-173.7)$ & 94.7 (20.4-138.7) & 0.097 \\
\hline $\begin{array}{l}\text { Median vaginal wall } \mathrm{D}_{8 c c}{ }^{+} \\
\left(\mathrm{EQD2} 2^{*}, \mathrm{~Gy} \text {, range) }\right.\end{array}$ & $94.7(32.4-144.4)$ & 80.7 (10.3-130.4) & 0.105 \\
\hline
\end{tabular}

${ }_{\mathrm{RT}}$ : radiation therapy.

"EQD2: equivalent dose in 2 Gy fractions.

${ }^{+}$D0.5cc, D1cc, D2cc, D4cc, D6cc, D8cc: most exposed 0.5, 1, 2, 4, 6, and $8 \mathrm{~cm} 3$ of tissue. scores of vaginal ulcer according to LENT-SOMA are summarized in Table 4. Two patients had superficial and $>1 \mathrm{~cm}^{2}$ vaginal ulcer and three had vaginal fistula (two vesicovaginal fistulae and one vesicovaginorectal fistula). Three out of the five patients had prior pelvic irradiation and the interval between prior pelvic irradiation and secondary pelvic irradiation was 15,27 , and 40 months, respectively. All of the three patients with vaginal fistula received hyperbaric oxygen therapy without success. Two underwent surgical intervention (one total cystectomy for massive hematuria and one nephrostomy) for their vesicovaginal fistula, while one was followed up conservatively with a persistent vesicovaginal fistula. The other two patients with grade 2 vaginal ulcer were treated conservatively. The overall 2-year actuarial incidence of vaginal ulcer was $11.4 \%$; $37.5 \%$ for re-irradiation patients and $5.6 \%$ for those without prior radiation therapy (Figure 1a). Comparison of dose-volume parameters of the vaginal wall is shown in Table 5 for the patient with and without vaginal ulcer. It was shown that the incidence of vaginal ulcer in the patients with prior pelvic irradiation was statistically higher than that of the patients without prior pelvic irradiation $(p=0.035)$. It was also shown that the mean $\mathrm{EQD}_{2}$ of vaginal wall $\mathrm{D}_{2 \mathrm{cc}}$ of patients with or without vaginal ulcer was statistically different $(p=0.025)$. There was no relationship between administration of concurrent chemotherapy and manifestation of vaginal ulcer $(p=0.256)$, number of needles used in HDR-ISBT $(p=0.293)$ nor bladder $D_{2 c c}$ $\mathrm{EQD}_{2}(p=0.091)$. The ROC analysis revealed that vaginal wall $D_{2 c c}$ was the best dosimetric parameter predicting the incidence of vaginal ulcer and the cutoff value of $145 \mathrm{~Gy}$ in vaginal wall $D_{2 \text { cc }}$ provided the lowest $p$ value in logrank test (Table 6). Figure 1b shows Kaplan-Meyer curve for the incidence of vaginal ulcer stratified by vaginal wall $\mathrm{D}_{2 \mathrm{cc}} 145 \mathrm{~Gy}$ in $\mathrm{EQD}_{2}$. The 2-year incidence rates of vaginal ulcer in the patients with vaginal wall $D_{2 \mathrm{cc}}$ equal to or less than $145 \mathrm{~Gy}$ in $\mathrm{EQD}_{2}$ and over 145 Gy were $3.7 \%$ and $23.5 \%$, respectively, with a statistically significant difference $(p=0.026)$.

\section{Discussion}

Although the Manchester method of ICBT for the cervical cancer was developed to avoid the occurrence of radiation induced vaginal ulcer and necrosis, vaginal ulcer is now very rarely encountered because vaginal wall is relatively radioresistant and typical ICBT delivers radiation dose less than the tolerance of the relatively radioresistant vaginal wall. In a retrospective study of cervical cancer patients using EBRT and the film based low-dose rate (LDR) brachytherapy, Samuel et al. showed that vaginal tolerance dose was above $150 \mathrm{~Gy}$ [15]. In recent advancement of image guided brachytherapy (IGBT), rectum and bladder doses were recommended to be 
Table 4 Patient characteristics who developed vaginal ulcer

\begin{tabular}{|c|c|c|c|c|c|c|c|c|}
\hline $\begin{array}{l}\text { Patient } \\
\text { no. }\end{array}$ & $\begin{array}{c}\text { Age at } \\
\text { HDR-ISBT }^{*}\end{array}$ & $\begin{array}{l}\text { Primary } \\
\text { site }\end{array}$ & Prior pelvic RT & $\begin{array}{c}\text { Interval between } \\
\text { prior RT and } \\
\text { HDR-ISBT' (mo) }^{*}\end{array}$ & $\begin{array}{c}\text { HDR-ISBT }^{*} \\
\text { with/without } \\
\text { EBRT }^{++}\end{array}$ & $\begin{array}{c}\text { Total vaginal wall } \\
\mathrm{D}_{0.5 \mathrm{cc}} / \mathrm{D}_{1 \mathrm{cc}}{ }^{\#} / \mathrm{D}_{2 \mathrm{cc}} \\
\text { in } \mathrm{EQD}_{2}^{\# \#}(\mathrm{~Gy})\end{array}$ & $\begin{array}{l}\text { LENT SOMA" } \\
\text { objective score }\end{array}$ & $\begin{array}{l}\text { LENT SOMA } \\
\text { management } \\
\text { score }\end{array}$ \\
\hline 1 & 40 & Cervix & $\begin{array}{l}\text { WPRT }{ }^{\dagger} 45 \mathrm{~Gy} / 25 \mathrm{fr}+ \\
\mathrm{EBRT}^{+\dagger} \text { boost } 15 \mathrm{~Gy} / 5 \mathrm{fr}\end{array}$ & 27 & HDR-ISBT 36 Gy/9fr & $272.1 / 202.6 / 169.1$ & 4 & 4 \\
\hline 2 & 51 & Cervix & None & None & $\begin{array}{r}\text { WPRT }^{\dagger} 30 \mathrm{~Gy} / 15 \mathrm{fr}+ \\
\mathrm{CS}^{\|} 20 \mathrm{~Gy} / 10 \mathrm{fr}+ \\
\text { HDR-ISBT }^{*} 24 \mathrm{~Gy} / 4 \mathrm{fr}\end{array}$ & 215.2/171.8/145.4 & 4 & 3 \\
\hline 3 & 64 & Corpus & None & None & $\begin{array}{l}\text { WPRT }^{\dagger} 30 \mathrm{~Gy} / 15 \mathrm{fr}+ \\
\text { HDR-ISBT }^{*} 30 \mathrm{~Gy} / 5 \mathrm{fr}\end{array}$ & 196.6/141.5/109.1 & 2 & 1 \\
\hline 4 & 64 & Cervix & $\begin{array}{r}\text { WPRT }^{\dagger} 40 \mathrm{~Gy} / 20 \mathrm{fr}+ \\
\mathrm{CS} 10 \mathrm{~Gy} / 5+\mathrm{HDR}-\mathrm{ICBT} \\
18 \mathrm{~Gy} / 3 \mathrm{fr}\end{array}$ & 40 & HDR-ISBT" 48 Gy/8fr & 465.4/352.1/294.4 & 2 & 1 \\
\hline 5 & 67 & Cervix & $\begin{array}{l}\text { WPRT }^{\dagger} 50 \text { Gy/50fr + } \\
\text { HDR-ICBT } 12 \text { Gy/3fr }\end{array}$ & 15 & HDR-ISBT 42 Gy/7fr & 234.0/211.1/193.5 & 4 & 3 \\
\hline
\end{tabular}

"HDR-ISBT: high-dose-rate interstitial brachytherapy.

tWPRT: whole pelvis radiation therapy.

${ }^{+\dagger} E B R T$ : external beam radiation therapy.

"CS: radiation therapy with center shielding.

"LENT-SOMA: Late Effects of Normal Tissues - Subjective, Objective, Management, Analytic.

"D0.5cc, D1cc, D2cc: most exposed 0.5, 1 and $2 \mathrm{~cm} 3$ of tissue.

\#\#ED2: equivalent dose in 2 Gy fractions.

reported in the treatment of ICBT for cervical cancer but vagina was not mentioned as OAR [9]. In the GECESTRO working group (II) or American Brachytherapy Society guidelines, vagina was taken into consideration for OAR but it was stated that the vaginal dose volume parameters still need to be defined [16,17]. Dimopoulos et al. reported clinical result of primary vaginal cancer treated with IGBT and they experienced two vaginal fistulae and one periurethral necrosis. However they did not specify DVH parameters of vaginal wall with vaginal complication [18]. Lee et al. reported in detail the toxicity analysis of CT based HDR-ISBT for gynecologic malignancies. They reported that $\mathrm{D}_{2 \mathrm{cc}}$ for the rectum was a reliable predictor of late rectal complication; however because of limited number of events it was not able to explore the DHV parameters for vaginal complication [5]. Recently, Vienna group tried to find out DVH parameters that correlate with vaginal late morbidities but vaginal $D_{2 c c}$ did not relate with the vaginal morbidities [12]. The calculation method was the same as

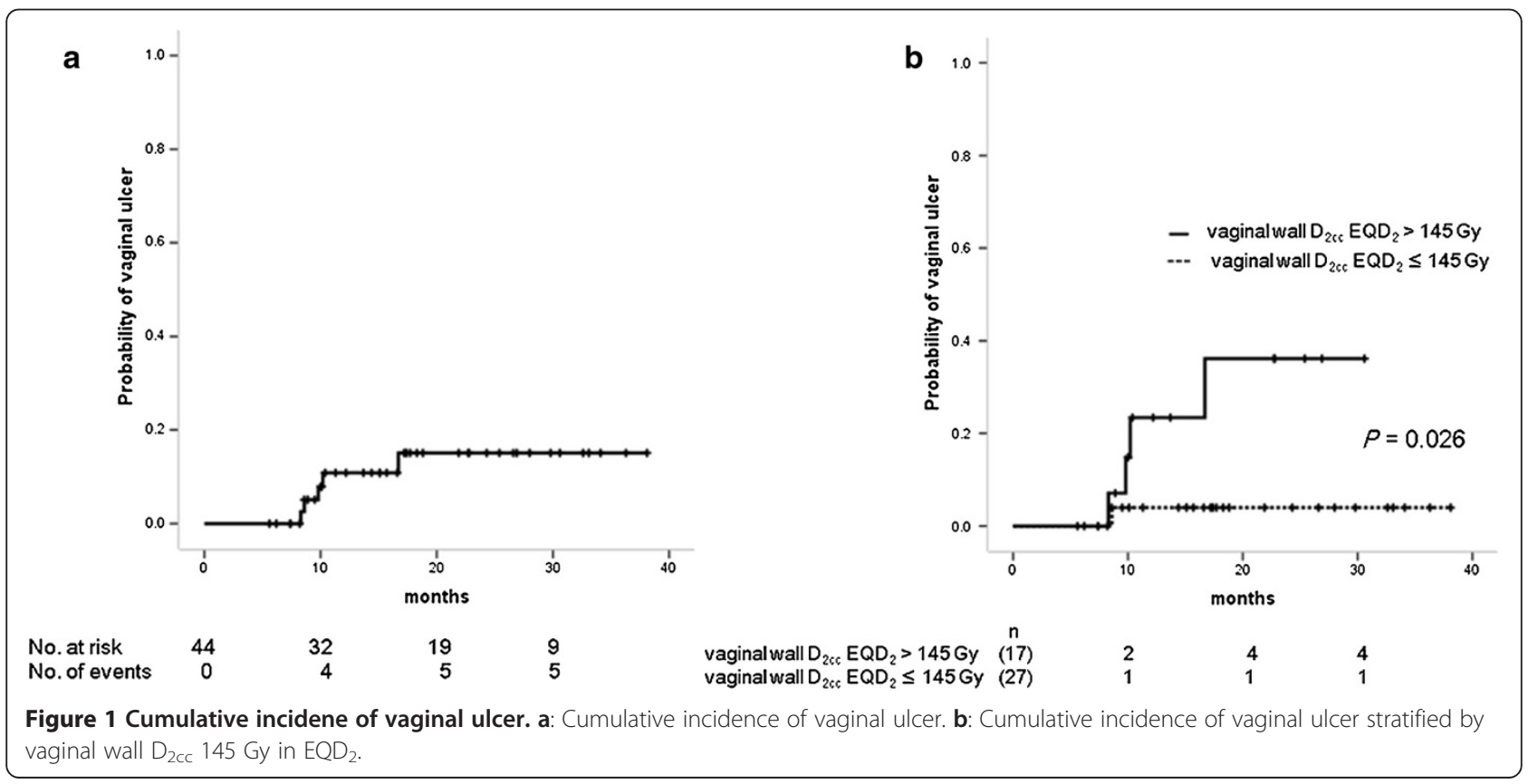


Table 5 Clinical predictors of vaginal ulcer

\begin{tabular}{|c|c|c|c|}
\hline \multirow{2}{*}{$\frac{\text { Characteristic }}{{\text { Prior pelvic } \mathrm{RT}^{*}}^{*}}$} & Vaginal ulcer $(+)(n=5)$ & Vaginal ulcer $(-)(n=39)$ & $p$ value \\
\hline & 3 & 5 & \\
\hline Yes & 2 & 34 & $0.035^{*}$ \\
\hline No & & & \\
\hline \multicolumn{4}{|l|}{ Concurrent chemotherapy } \\
\hline Yes & 0 & 10 & 0.256 \\
\hline No & 5 & 29 & \\
\hline Median number of needles used in HDR-ISBT (range) & $14(10-24)$ & $15(5-29)$ & 0.293 \\
\hline Median $\mathrm{CTV}^{\dagger}$ ( $\mathrm{ml}$, range) & $54.7(17.7-114.0)$ & $34.7(2.4-142.1)$ & 0.271 \\
\hline Median rectum $\mathrm{D}_{2 c c}{ }^{\dagger+}$ (EQD ${ }_{2}{ }^{\|}, \mathrm{Gy}$, range) & $84.2(34.0-100.7)$ & $57.9(30.5-114.3)$ & 0.118 \\
\hline Median bladder $\mathrm{D}_{2 \subset c}{ }^{\dagger \dagger}\left(\mathrm{EQD}_{2}{ }^{\|}, \mathrm{Gy}\right.$, range) & $69.3(37.4-113.5)$ & $57.7(7.3-120.3)$ & 0.091 \\
\hline Median vaginal wall $\mathrm{D}_{0.5 c c}{ }^{\dagger+}\left(\mathrm{EQD}_{2}{ }^{\|}, \mathrm{Gy}\right.$, range) & $206.4(106.6-349.3)$ & $149.4(47.9-310.1)$ & 0.243 \\
\hline Median vaginal wall $\mathrm{D}_{1 \subset c}{ }^{\dagger \dagger}\left(E \mathrm{ED}_{2} \|, \mathrm{Gy}\right.$, range) & $169.1(91.6-277.5)$ & $127.9(33.6-220.8)$ & 0.096 \\
\hline Median vaginal wall $\mathrm{D}_{2 c c}{ }^{\dagger \dagger}\left(\mathrm{EQD}_{2} \|, \mathrm{Gy}\right.$, range) & $152.5(71.1-247.5)$ & $109.0(31.7-201.9)$ & $0.025^{*}$ \\
\hline Median vaginal wall $\mathrm{D}_{4 \subset c}{ }^{\dagger \dagger}\left(\mathrm{EQD}_{2} \|, \mathrm{Gy}\right.$, range) & $115.5(83.8-200.8)$ & $110.6(34.0-153.2)$ & 0.152 \\
\hline Median vaginal wall $\mathrm{D}_{6 c c}{ }^{\dagger+}\left(\mathrm{EQD}_{2} \|, \mathrm{Gy}\right.$, range) & $102.5(60.4-173.7)$ & $99.5(20.4-146.3)$ & 0.266 \\
\hline Median vaginal wall $\mathrm{D}_{8 \mathrm{cc}}{ }^{\dagger+}\left(\mathrm{EQD}_{2}{ }^{\|}, \mathrm{Gy}\right.$, range) & $82.0(47.6-144.4)$ & $84.3(10.3-140.3)$ & 0.511 \\
\hline
\end{tabular}

"RT: radiation therapy.

JHDR-ISBT.

${ }^{\dagger} \mathrm{CTV}$ : clinical target volume.

EQD2: equivalent dose in 2 Gy fractions.

${ }^{+\dagger}$ D0.5cc, D1cc, D2cc, D4cc, D6cc, D8cc: most exposed 0.5, 1, 2, 4, 6, and $8 \mathrm{~cm} 3$ of tissue.

the current study, which was composed of EBRT and ICBT/ISBT and normalized to 2 Gy per fraction $\left(\mathrm{EQD}_{2}\right)$ using the linear-quadratic model with $\alpha / \beta$ of 3 Gy for the vaginal morbidities [10-12,16]. The difference between Vienna group and the current study was that there were more patients with severe vaginal morbidities in the current study, presumably because there were more patients who received re-irradiation and current study excluded the patients treated with HDR-ICBT. HDR-ISBT delivers higher dose to the vaginal wall than HDR-ICBT because the multiple needle applicators directly contact vaginal wall. According to the current results, after vaginal wall $\mathrm{D}_{0.5 \mathrm{cc},} \mathrm{D}_{1 \mathrm{cc},} \mathrm{D}_{2 \mathrm{cc},}, \mathrm{D}_{4 \mathrm{cc}}, \mathrm{D}_{6 \mathrm{ccc}}$, and $\mathrm{D}_{8 \mathrm{cc}}$ having been compared, vaginal wall $\mathrm{D}_{2 \mathrm{cc}}$ was found to be the most relevant DVH parameter predicting the incidence of vaginal ulcer. ROC analysis also showed that vaginal wall $\mathrm{D}_{2 \mathrm{cc}}$ of $145 \mathrm{~Gy}$ in $\mathrm{EQD}_{2}$ can be used as clinical cutoff dose predicting vaginal ulcer. This figure is quite similar to the vaginal tolerance dose of 150 Gy derived from a retrospective study of LDR brachytherapy which was previously mentioned [15]. The current report is the first one concerning about vaginal DVH parameter and complication using modern era of three-dimensional image-guided brachytherapy. It was also found in this study that the history of prior pelvic irradiation was another significant predictive factor for vaginal ulcer (Table 5). Lee et al. reported a patient with colovaginal fistula with previous EBRT [5,7]. As shown in Table 3,
Table 6 Dosimetric predictors for the development of vaginal ulcer

\begin{tabular}{|c|c|c|c|c|}
\hline Parameter & $\operatorname{ROC}^{\dagger} \mathrm{AUC}^{*}$ & Cutoff" & $\begin{array}{l}\text { 2-y incidence } \\
\text { ofvaginal } \\
\text { ulcer }(\%)\end{array}$ & P value \\
\hline \multirow{2}{*}{$\begin{array}{l}\text { Vaginal wall } \\
D_{0.5 c c} \|\left(E Q D_{2}{ }^{\dagger+}\right)\end{array}$} & 0.667 & $\leq 195 \mathrm{~Gy}$ & 0.0 & 0.058 \\
\hline & & >195 Gy & 18.5 & \\
\hline \multirow{2}{*}{$\begin{array}{l}\text { Vaginal wall } \\
D_{1 c c} \|\left(E Q D_{2}{ }^{\dagger+}\right)\end{array}$} & 0.682 & $\leq 171 \mathrm{~Gy}$ & 4.2 & 0.091 \\
\hline & & $>171 \mathrm{~Gy}$ & 20.0 & \\
\hline \multirow{2}{*}{$\begin{array}{l}\text { Vaginal wall } \\
D_{2 c c} \|\left(E Q D 2^{+\dagger}\right)\end{array}$} & 0.733 & $\leq 145 \mathrm{~Gy}$ & 3.7 & $0.026^{*}$ \\
\hline & & >145 Gy & 23.5 & \\
\hline \multirow{2}{*}{$\begin{array}{l}\text { Vaginal wall } \\
D_{4 \subset c} \|\left(E Q D_{2}{ }^{+\dagger}\right)\end{array}$} & 0.618 & $\leq 83 \mathrm{~Gy}$ & 0.0 & 0.119 \\
\hline & & $>83 \mathrm{~Gy}$ & 15.6 & \\
\hline \multirow{2}{*}{$\begin{array}{l}\text { Vaginal wall } \\
D_{6 c c} \|\left(E Q D_{2}^{+\dagger}\right)\end{array}$} & 0.569 & $\leq 86$ Gy & 5.6 & 0.323 \\
\hline & & $>86$ Gy & 15.4 & \\
\hline \multirow{2}{*}{$\begin{array}{l}\text { Vaginal wall } \\
D_{8 c c} \|\left(E^{+\dagger} D_{2}^{+\dagger}\right)\end{array}$} & 0.559 & $\leq 75$ Gy & 5.6 & 0.323 \\
\hline & & $>75$ Gy & 15.4 & \\
\hline
\end{tabular}

"AUC: area under the curve.

${ }^{\dagger} \mathrm{ROC}$ : receiver operator characteristic.

${ }^{+\dagger} \mathrm{EQD2}$ : equivalent dose in $2 \mathrm{~Gy}$ fractions.

"D0.5cc, D1cc, D2cc, D4cc, D6cc, D8cc: most exposed 0.5, 1, 2, 4, 6, and $8 \mathrm{~cm} 3$ of tissue.

"Cutoff refers to the most predictive value from the AUC of ROC curve.

"Univariate analysis by log-rank test. 
both rectum and bladder $D_{2 c c}$ was significantly higher in patients with prior pelvic irradiation than those without prior pelvic irradiation. However both rectum and bladder $\mathrm{D}_{2 \mathrm{cc}}$ was not in itself a significant prognostic factor for vaginal ulcer and could not be used as a surrogate indicator (Table 5).

There were several limitations in this study. Contouring of the vagina was not based on MRI but CT, which is inferior to MRI in tissue contrast. However because 41 out of 44 patients were inserted either cylinder or mold into their vagina, contouring of vagina was considered to be precise. The time interval between the prior pelvic RT and HDR-ISBT was not taken into consideration for the calculation of the total dose for OARs. Additionally, this study was a retrospective study with small number of patients with heterogeneous tumor origin, heterogeneous treatment applied, small number of events, and with short follow-up period. Therefore we should be cautious about the results of the current study. However even tumor origin differed greatly in current cohorts of study, it is considered to be feasible because the main concern in current study was focused on only the vaginal toxicity.

It should be stressed that with the introduction of HDR-ISBT in gynecological malignancies and increment of vaginal dose, vaginal tolerance dose must be taken into consideration. Further discussion and validation of vaginal DVH parameters in image-guided brachytherapy in a multicenter prospective study is needed.

\section{Conclusions}

The DVH parameters for vagina are essential for treatment planning and optimization in image based HDRISBT in gynecological malignancies. Vaginal wall $D_{2 c c}$ in $\mathrm{EQD}_{2}$ should be monitored and be kept under 145 Gy in order to avoid vaginal ulcer. Also in patients with prior pelvic irradiation, vaginal wall dose including the prior radiation dose should be kept lower than $145 \mathrm{~Gy}$.

\section{Consent}

Written informed consent was obtained from the patient for the publication of this report and any accompanying images.

\footnotetext{
Abbreviations

HDR-ISBT: High-dose rate interstitial brachytherapy; $\mathrm{EQD}_{2}$ : Dose in equivalent in 2 Gy fractions; ICBT: Intracavitary brachytherapy; ISBT: Interstitial brachytherapy; DVH: Dose volume histogram; EBRT: External beam radiation therapy; GTV: Gross tumor volume; CTV: Clinical target volume; OAR: Organ at risk; AUC: Area under the curve; ROC: Receiver operating characteristics; IGBT: Image guided brachytherapy; PDR: Pulsed dose rate.
}

\section{Competing interests}

The authors declare that they have no competing interests.

\section{Authors' contributions}

TK, MS, RY, KH, MK, SS, KT, KY, Kl, MM, and Yl performed the treatment. NM and $\mathrm{Jl}$ analyzed the data and wrote the manuscript. All authors read and approved the final manuscript.

\section{Acknowledgement}

Part of this study was financially supported by Cancer Research and Development Fund 23-A-13 of National Cancer Center.

\section{Author details}

'Department of Radiation Oncology, National Cancer Center Hospital, 5-1-1, Tsukiji Chuo-ku, Tokyo 104-0045, Japan. ${ }^{2}$ Department of Gynecologic Oncology, National Cancer Center Hospital, 5-1-1, Tsukiji Chuo-ku, Tokyo 104-0045, Japan. ${ }^{3}$ Department of Radiology, Showa University School of Medicine, 1-5-8, Hatanodai Shinagawa-ku, Tokyo 142-8666, Japan.

Received: 21 July 2013 Accepted: 19 January 2014

Published: 23 January 2014

\section{References}

1. Martinez A, Cox RS, Edmundson GK: A multiple-site perineal applicator (MUPIT) for treatment of prostatic, anorectal, and gynecologic malignancies. Int J Radiat Oncol Biol Phys 1984, 10:297-305.

2. Stock RG, Chan K, Terk M, Dewyngaert JK, Stone NN, Dottino P: A new technique for performing Syed-Neblett template interstitial implants for gynecologic malignancies using transrectal-ultrasound guidance. Int J Radiat Oncol Biol Phys 1997, 37:819-825.

3. Martinez A, Edmundson GK, Cox RS, Gunderson LL Howes AE: Combination of external beam irradiation and multiple-site perineal applicator (MUPIT) for treatment of locally advanced or recurrent prostatic, anorectal, and gynecologic malignancies. Int I Radiat Oncol Biol Phys 1985, 11:391-398.

4. Erickson B, Albano K, Gillin M: CT-guided interstitial implantation of gynecologic malignancies. Int J Radiat Oncol Biol Phys 1996, 36:699-709.

5. Lee L, Damato AL, Viswanathan AN: Clinical outcomes of high-dose-rate interstitial gynecologic brachytherapy using real-time $\mathrm{CT}$ guidance. Brachytherapy 2013, 12:303-310.

6. Georg P, Lang S, Dimopoulos JC, et al: Dose-volume histogram parameters and late side effects in magnetic resonance image-guided adaptive cervical cancer brachytherapy. Int J Radiat Oncol Biol Phys 2011, 79:356-362

7. Lee LJ Viswanathan AN: Predictors of Toxicity After Image-guided High-dose-rate Interstitial Brachytherapy for Gynecologic Cancer. Int J Radiat Oncol Biol Phys 2012, 84:1192-1197.

8. Bethesda M: ICRU report 38. Dose and volume specification for reporting intracavitary therapy in gynecology. International Commission on Radiation Units and Measurements 1985, 38:1-20.

9. Itami J, Hara R, Kozuka T, et al: Transperineal high-dose-rate interstitial radiation therapy in the management of gynecologic malignancies. Strahlenther Onkol 2003, 179:737-741.

10. Dale RG: The application of the linear-quadratic dose-effect equation to fractionated and protracted radiotherapy. Br J Radiol 1985, 58:515-528.

11. Bentzen SM, Dorr W, Gahbauer R, et al: Bioloeffect modeling and effective dose concepts in radiation oncology - Terminology, quantities and units. Radiother Oncol 2012, 105:266-268.

12. Fidarova EF, Berger D, Schussler $\mathrm{S}$, et al: Dose volume parameter D2cc does not correlate with vaginal side effects in individual patients with cervical cancer treated within a defined treatment protocol with very high brachytherapy doses. Radiother Oncol 2010, 97:76-79.

13. LENT SOMA scales for all anatomic sites. Int I Radiat Oncol Biol Phys 1995, 31:1049-1091.

14. Akobeng AK: Understanding diagnostic tests 3 : receiver operating characteristic curves. Acta Paediatr 2007, 96:644-647.

15. Samuel P, Perry W, Grigsby: The irradiation tolerance dose of the proximal vagina. Radiother Oncol 2007, 67:77-85.

16. Potter R, Haie-Meder C, Van Limbergen E, et al: Recommendations from gynaecological (GYN) GEC ESTRO working group (II): concepts and terms in 3D image based treatment planning in cervix cancer brachytherapy 3D dose volume parameters and aspects of 3D image based anatomy, radiation physics, radiobiology. Radiother Oncol 2006, 78:67-77. 
17. Viswanathan AN, Thomadsen B: American Brachytherapy Society concensus guidelines for locally advanced carcinoma of the cervix. Part I: General principles. Brachytherapy 2012, 11:33-46.

18. Dimopoulos JCA, Schmid MP, Fidarova E, et al: Treatment of locally advanced vaginal cancer with radiochemotherapy and magnetic resonance image-guided adaptive brachytherapy: dose-volume parameters and first clinical results. Int J Radiat Oncol Biol Phys 2012, 82:1880-1888.

doi:10.1186/1748-717X-9-31

Cite this article as: Murakami et al:: Vaginal tolerance of CT based

image-guided high-dose rate interstitial brachytherapy for

gynecological malignancies. Radiation Oncology 2014 9:31.

\section{Submit your next manuscript to BioMed Central and take full advantage of:}

- Convenient online submission

- Thorough peer review

- No space constraints or color figure charges

- Immediate publication on acceptance

- Inclusion in PubMed, CAS, Scopus and Google Scholar

- Research which is freely available for redistribution 